\title{
Laser-driven synthesis and magnetic properties of iron nanoparticles
}

\author{
Yuanqing $\mathrm{He}^{1,4}$, Yudhisthira Sahoo ${ }^{2,4}$, Shumin Wang ${ }^{3}$, Hong Luo ${ }^{3,4}$, Paras N. Prasad ${ }^{2,3,4}$ and \\ Mark T. Swihart ${ }^{1,4, *}$ \\ ${ }^{1}$ Department of Chemical and Biological Engineering, University at Buffalo, The State University of New \\ York, Buffalo, NY 14260, USA; ${ }^{2}$ Department of Chemistry, University at Buffalo, The State University \\ of New York, Buffalo, NY 14260, USA; ${ }^{3}$ Department of Physics, University at Buffalo, The State University \\ of New York, Buffalo, NY 14260, USA; ${ }^{4}$ Institute for Lasers, Photonics and Biophotonics, University at \\ Buffalo, The State University of New York, Buffalo, NY 14260, USA; *Author for correspondence (Tel.: \\ +1-716-645-2911; Fax: +1-716-645-3822; E-mail: swihart@eng.buffalo.edu)
}

Received 30 September 2004; accepted in revised form 6 July 2005

Key words: $\mathrm{CO}_{2}$ laser, aerosol synthesis, magnetic, iron, nanoparticle

\begin{abstract}
Nanoparticles of iron have been prepared by laser-driven decomposition of iron pentacarbonyl vapor. In this method, an infrared laser rapidly heats a dilute mixture of precursor vapors to decompose the precursor and initiate particle nucleation. It was found that when using $\mathrm{SF}_{6}$ as a photosensitizer during the synthesis, ferrous fluoride $\left(\mathrm{FeF}_{2}\right)$ was produced as an undesired byproduct in the product powder. The particle size, composition, and crystalline structure have been characterized using X-ray diffraction (XRD), transmission electron microscopy (TEM), selected area electron diffraction (SAED), and X-ray photoelectron spectroscopy (XPS). Results of magnetization measurements for small iron nanoparticles (about $5 \mathrm{~nm}$ diameter) are also presented, showing superparamagnetic behavior at room temperature, and a blocking temperature near $125 \mathrm{~K}$.
\end{abstract}

\section{Introduction}

Currently, magnetic nanoparticles such as iron, nickel and cobalt, are used in recording tape and flexible disk recording media. A variety of other applications, including environmental remediation (Zhang, 2003) and biomedical applications (Pankhurst et al., 2003; Plank et al., 2003; Tartaj et al., 2003) have been proposed. As a result, a significant amount of work has been done to study the preparation and magnetic properties of such particles (Menendez et al., 2002). A number of techniques have been used for the production of iron nanoparticles, such as inert gas evaporation (Jonsson et al., 1996), chemical vapor condensa- tion (Choi et al., 2002; Dong et al., 2002; McIlroy et al., 2003; Signoretti et al., 2003), sol-gel methods (Hseih et al., 2002), sonochemisty (Pol et al., 2003; Li et al., 2003a), wet chemical methods (Chen et al., 2004; Huber et al., 2004), and laserdriven thermal methods (Zhao et al., 1994; Cireasa et al., 1996; Veintemillas-Verdaguer et al., 2003). There has also been significant work on combining iron with other metals or semiconductor to form nanoparticles of alloys or compounds with particular desired properties, such as Fe-Si (Martelli et al., 2002), Fe-Al (Pithawalla et al., 2001), Fe-Ni (Ge et al., 1997), Fe-Pt (Jeyadevan et al., 2003; Held et al., 2004), Fe-Co (Choi et al., 2001; Wu et al., 2003; Li et al., 2003a), Ti-Fe (Ye et al., 1997), and 
Fe-Au (Andres et al., 2003; Chen et al., 2003; Kinoshita et al., 2003). In the present work, we are interested in the preparation and characterization of iron nanoparticles formed by laser-driven pyrolysis of iron carbonyl $\left(\mathrm{Fe}(\mathrm{CO})_{5}\right)$ vapors.

$\mathrm{CO}_{2}$ laser pyrolysis of different CVD precursors has proven to be a successful method for preparation of nanoparticles of a variety of materials (Cannon et al., 1982a, b; Zhao et al., 1994; Martelli et al., 2002; Li et al., 2003b). Laser-driven pyrolysis of gaseous precursors for preparation of iron and iron oxide nanoparticles has been reported during the past few years, and the magnetic properties of these particles have also been studied (Zhao et al., 1994; Cireasa et al., 1996; Alexandrescu et al., 1998; Veintemillas-Verdaguer et al., 1998, 2002, 2003). Colloidal synthesis of magnetic iron oxide nanoparticles is also relatively straightforward and has been widely reported. There are several major advantages of vapor phase synthesis over colloidal/solution synthesis methods. First and foremost, no solvent is needed. This allows higher purity in the product, since gases and volatile liquids are easily purified by distillation, whereas purification of nonvolatile solvents is more difficult. This also eliminates solvent disposal or recycling, which can be a major cost if solution-phase syntheses are scaled up. Vapor phase methods also provide high throughput, since particle formation typically takes place on a time scale of milliseconds rather than a time scale of minutes or hours that is more typical of solution methods. Particles can be collected directly from the vapor phase onto filters, without requiring any further separation or drying procedure. In the laser-driven aerosol synthesis reactor used in the studies described here, an infrared laser rapidly (in less than 1 millisecond) heats a mixture of precursor vapor in inert gas to decompose the precursor and initiate particle nucleation. The laser heating allows for rapid cooling of the freshly nucleated particles by mixing with unheated gas. This quenches their growth at controllable sizes, typically from 2 to $50 \mathrm{~nm}$ in diameter.

\section{Experimental}

The reactor configuration shown in Figures 1 and 2 was used to prepare iron nanoparticles in the experiments described here. About $15 \mathrm{ml}$ of $\mathrm{Fe}(\mathrm{CO})_{5}$ was sealed in a home-built stainless steel

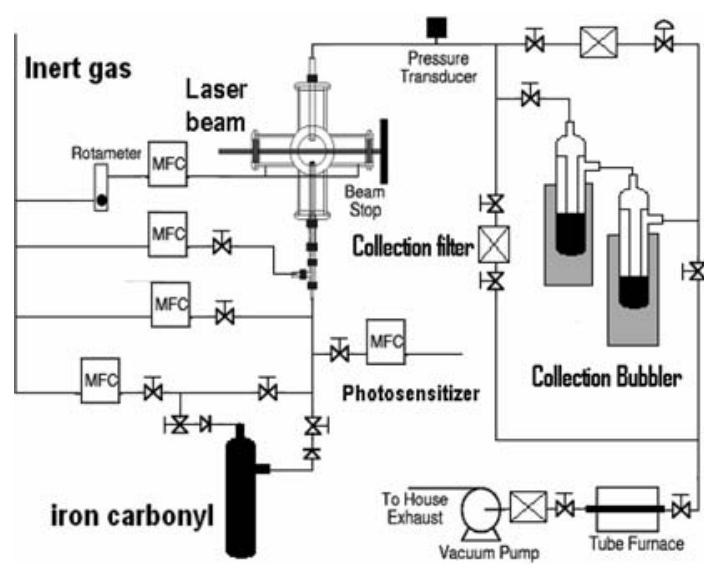

Figure 1. Schematic drawing of the reactor system for producing $\mathrm{Fe}$ nanoparticles by laser-driven decomposition of $\mathrm{Fe}(\mathrm{CO})_{5}$.

bubbler with check valves at the inlet and outlet. The vapor pressure of $\mathrm{Fe}(\mathrm{CO})_{5}$ is high enough at room temperature ( $\sim 25$ Torr) to provide an adequate flow of $\mathrm{Fe}(\mathrm{CO})_{5}$ to the reactor system. The $\mathrm{Fe}(\mathrm{CO})_{5}$ delivery rate is, therefore, controlled by the carrier gas flow, while holding the bubbler at

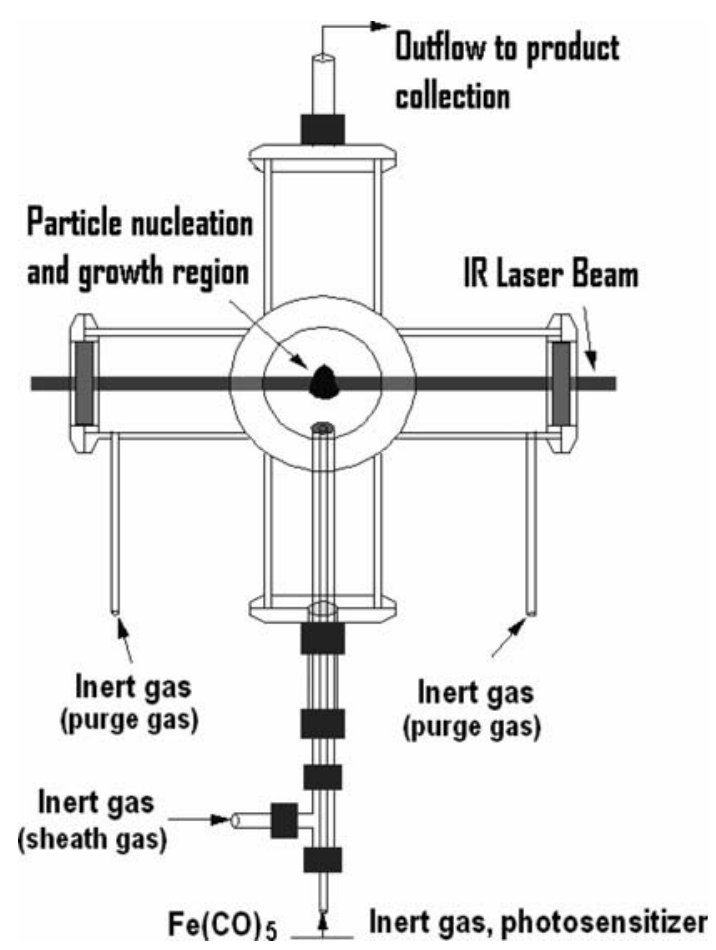

Figure 2. Schematic drawing of the reactor. 
room temperature. The $\mathrm{Fe}(\mathrm{CO})_{5}$ stream from the generator was mixed with an inert gas (like argon) and a photosensitizer gas (sulfur hexafluoride or ethylene) before entering the reactor. A continuous $\mathrm{CO}_{2}$ laser beam (Coherent, Model 42 laser emitting up to 60 Watts) was focused to reduce the size of the reaction zone to $1-3 \mathrm{~mm}$ in diameter just above the central reactant inlet, which is made from $1 / 8$ inch O.D. tubing centered within a piece of $3 / 8$ inch O.D. tubing through which a sheath flow of inert gas enters the reactor. This sheath gas helps to confine the reaction zone to a small region near the axis of the reactor. In all experiments described here, the laser output was near its maximum value of 60 Watts. A photosensitizer is needed because iron carbonyl does not absorb light at the laser wavelength of 10.6 microns. $\mathrm{SF}_{6}$ (technical grade, Aldrich) has a large absorption cross-section at the laser wavelength and is stable at high temperatures. The $\mathrm{SF}_{6}$ molecules absorb the laser energy and transfer it to the precursor and other gaseous molecules, resulting in very rapid heating of the gas stream. Argon (UHP, passed through an oxygen trap to remove residual $\mathrm{O}_{2}$ and $\mathrm{H}_{2} \mathrm{O}$ ) flows confine the reactant and photosensitizer $\left(\mathrm{SF}_{6}\right)$ to a region near the axis of the reactor and prevent them from accumulating in the arms of the 6-way cross from which the reactor is constructed. These streams entering at the ends of the horizontal arms of the reactor are referred to as the purge gas flows, while the gas entering in the outer portion of the concentric nozzle is referred to as the sheath gas in the remainder of this manuscript. If the sheath gas does not contain any photosensitizer, then it is not heated by the laser. Mixing of the heated particle-containing gas with this cool sheath gas and, eventually, with the purge gas, results in rapid cooling of the freshly formed particles, preventing their coalescence into larger particles. This is essential for producing small particles at high throughput. All gas flow rates to the reactor are controlled by mass flow controllers. The resulting particles are collected on cellulose nitrate membrane filters. Particles can also be collected directly into a surfactant solution using a bubbler connected in parallel with the collection filter. The solvent used for particle collection was usually toluene with surfactants (octadecylamine and/or oleic acid) added to improve particle dispersion. Iron nanopowders oxidize violently upon exposure to air, but these particles could be protected from oxidation by collecting them directly into surfactant solution in the bubbler.

Wide-angle powder X-ray diffraction (XRD, Siemens D500) was used to characterize iron nanoparticles stored in toluene (HPLC grade, T. J. Baker) in order to avoid oxidation of iron upon exposure to air. Transmission electron microscopy (TEM) was performed using a JEOL JEM 2010 microscope at an acceleration voltage of $200 \mathrm{kV}$ to characterize particle size and morphology. Samples were prepared for TEM imaging by dispersing them in toluene in a glove box to prevent violent oxidation in air and then evaporating drops of the dispersion on a carbon-coated TEM grid. Selected-area electron diffraction was performed in the TEM to determine the crystalline structure. X-Ray Photoelectron Spectroscopy (XPS) (also called Electron Spectroscopy for Chemical Analysis, or ESCA) was performed on a Physical Electronics/ PHI 5300 X-ray photoelectron spectrometer for elemental analysis of the surface of the powder samples. DC magnetization measurements were made using a superconducting quantum interference device (SQUID) MPMS C-151 magnetometer from Quantum Design. The powder sample was dispersed in hexadecane and put in a non-magnetic gel capsule that was then wrapped with layers of Teflon tape to prevent breakage under vacuum. The magnetic field was ramped from 0 to $3000 \mathrm{Oe}$ at both 300 and $5 \mathrm{~K}$.

\section{Results and discussion}

In the present work, the iron particles were collected both into surfactant-containing solution in bubblers and as powders on cellulose nitrate membrane filters. Two bubblers were used during the experiments for which results are shown below. The first one contained $15 \mathrm{ml}$ pure toluene, and the second one, located downstream of the first, contained a small amount of surfactant, oleic acid (90\%, Aldrich) and/or octadecylamine (97\%, Aldrich) in $15 \mathrm{ml}$ toluene. Operating parameters used in the experiments reported here are shown in Table 1. The production rate of iron nanoparticles was roughly $100 \mathrm{mg}$ per hour in these experiments. The results presented here are from two representative experiments selected from a large number of similar experiments performed. They have been 
Table 1 Reaction parameters used for making iron nanoparticles

\begin{tabular}{|c|c|c|c|c|c|c|c|}
\hline $\begin{array}{l}\text { Operating } \\
\text { Pressure } \\
\text { (psia) }\end{array}$ & $\begin{array}{l}\mathrm{SF}_{6} \text { (inlet) } \\
\text { flow rate } \\
(\mathrm{sccm})\end{array}$ & $\begin{array}{l}\mathrm{C}_{2} \mathrm{H}_{4} \text { (inlet) } \\
\text { flow rate } \\
(\mathrm{sccm})\end{array}$ & $\begin{array}{l}\text { Ar flow rate } \\
\text { to } \mathrm{Fe}(\mathrm{CO})_{5} \\
\text { bubbler } \\
(\mathrm{sccm})\end{array}$ & $\begin{array}{l}\text { Ar (inlet) } \\
\text { flow rate } \\
(\mathrm{sccm})\end{array}$ & $\begin{array}{l}\text { Ar (sheath) } \\
\text { flow rate } \\
(\mathrm{sccm})\end{array}$ & $\begin{array}{l}\text { Purge Ar } \\
\text { flow rate } \\
(\mathrm{sccm})\end{array}$ & Surfactant \\
\hline \multicolumn{8}{|c|}{ Experiment (1) } \\
\hline$\sim 8.0$ & 2.6 & & 10.2 & 290 & 360 & 2200 & $\begin{array}{l}0.5 \mathrm{ml} \text { Oleic } \\
\text { acid in } 15 \mathrm{ml} \\
\text { toluene }\end{array}$ \\
\hline \multicolumn{8}{|c|}{ Experiment (2) } \\
\hline$\sim 7.0$ & & 150 & 10.2 & 0 & 360 & 2200 & $\begin{array}{l}16 \mathrm{mg} \\
\text { Octadecylamine } \\
\text { in } 15 \mathrm{ml} \text { toluene }\end{array}$ \\
\hline
\end{tabular}

selected to demonstrate the capabilities of this technique and to highlight the effect of the photosensitizer. The change in surfactant between experiments 1 and 2 is not of great importance, though the amine was found to be slightly more effective in dispersing the particles than the carboxylic acid. In experiment (2) the argon flow to the precursor inlet was not used, because of the large flow of $\mathrm{C}_{2} \mathrm{H}_{4}$ required for effective photosensitization. $\mathrm{C}_{2} \mathrm{H}_{4}$ is a much weaker absorber of the laser radiation, and therefore a much larger flow rate of it, compared to $\mathrm{SF}_{6}$ was required.

All powder samples of iron nanoparticles burned to form red powders when exposed to air. Therefore, XRD was used to characterize the iron nanoparticles dispersed in toluene. Figure 3 shows the X-ray diffraction pattern from the iron sample that was prepared in experiment (1). The sample showed the major characteristic peaks for pure

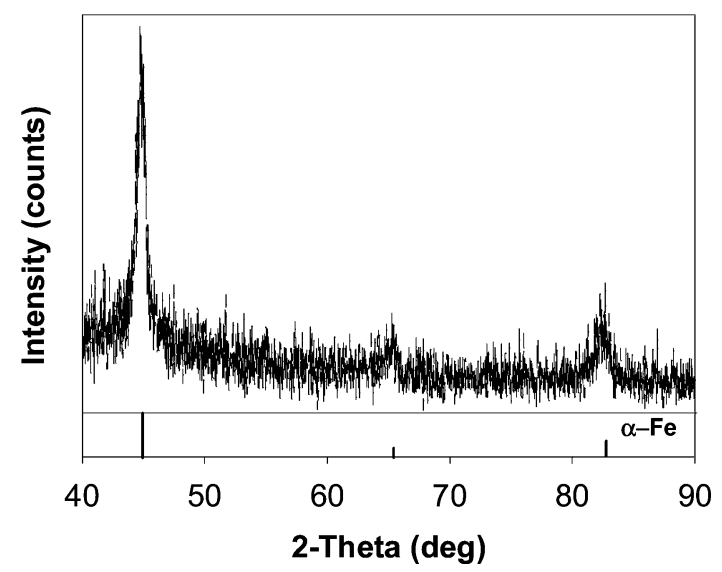

Figure 3. X-Ray Diffraction pattern of iron sample (stored under toluene, 0.33 mil Kapton film covered). crystalline metallic iron at $2-\theta$ values of $44.7,65.2$ and 82.3 degrees. This indicates that there is no significant amount of crystalline iron oxide or other crystalline material formed. Samples of nanoparticles that had been collected directly into solution were characterized with TEM and SEAD. Figures 4 and 5 show TEM images of and SAED patterns from iron particles collected in pure toluene in the first bubbler. The sample collected in the second bubbler, with surfactant, shows the same SAED pattern. However, the TEM images of that sample are less clear, since residual oleic acid that is present along with the particles on the TEM

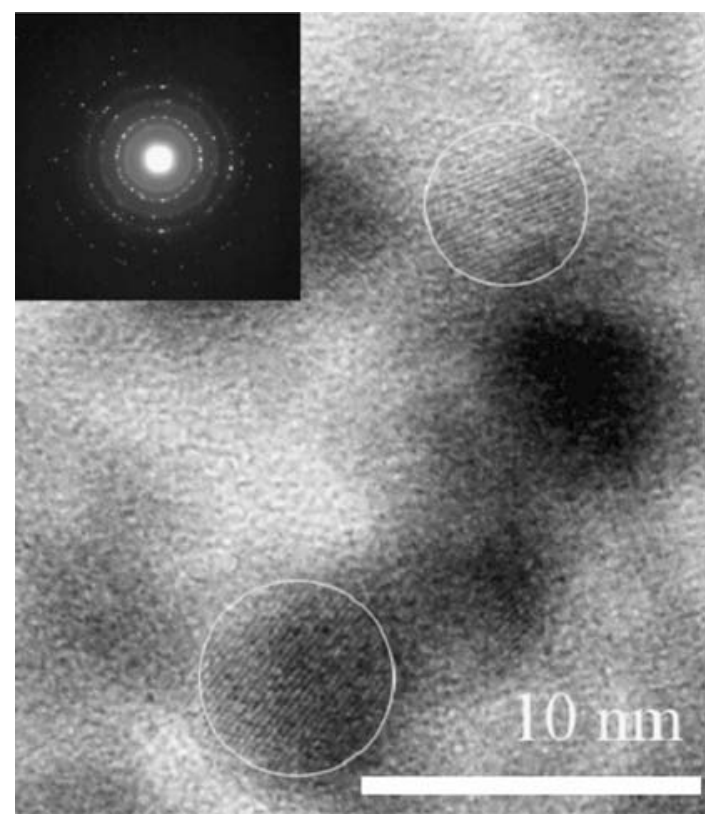

Figure 4. TEM image $(110 \alpha-\mathrm{Fe})$ and SAED pattern from iron particles collected in bubbler in experiment (1). 


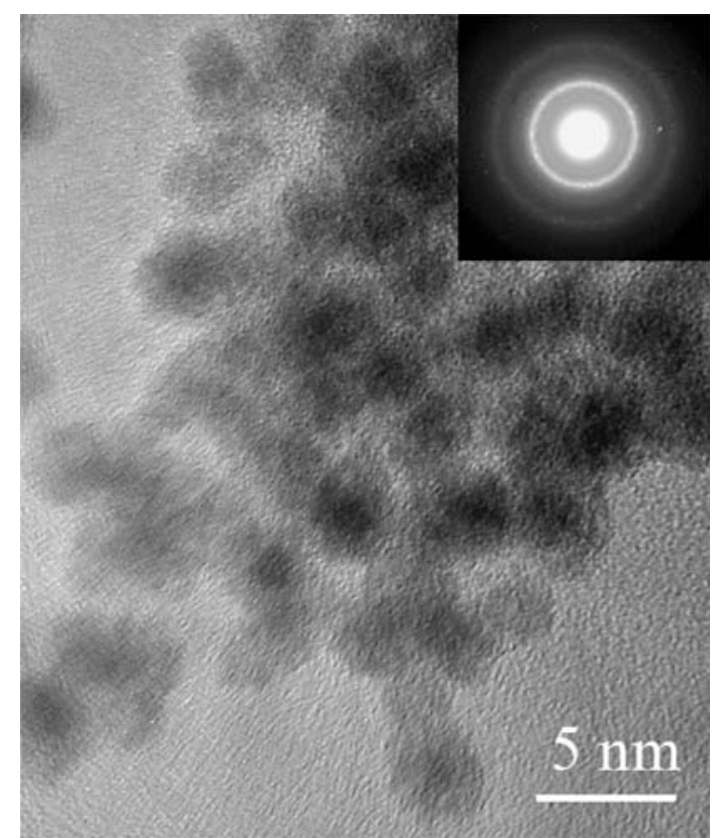

Figure 5. TEM image and SAED pattern from iron particles collected in a bubbler in experiment (2).

grid interferes with the high-resolution imaging. The primary particle size of these particles is below $10 \mathrm{~nm}$ in diameter, as seen in the TEM images.

The crystalline structure of the nanoparticles can be determined from the SAED pattern. The electron diffraction pattern exhibits rings due to both iron and iron oxide phases. For $\alpha$-iron with the expected bcc crystallographic phase the lowest index ring will be 110 followed by 200, 211, 220 etc., with corresponding diameter ratios of 1:1.414:1.732:2 etc. Similarly, for the fcc $\mathrm{Fe}_{3} \mathrm{O}_{4}$ and $\mathrm{Fe}_{2} \mathrm{O}_{3}$, the expected diffraction rings correspond to the $111,200,220,311,222$ etc. planes with corresponding diameter ratios of 1:1.16:1.63:1.92:2.0. These diameter ratios were used to index the rings in Figures 4 and 5. The diameters of the second, third, fourth, fifth, and sixth rings observed in the inset of figure 4 obey the expected ratios for $\alpha$-iron. Conversion of the ring diameters to lattice spacings using the camera constant for the TEM gives the expected values for $\alpha$-Fe (2.03 $\AA$ spacing for 110 planes, etc.). The smallest complete ring in the inset of Figure 4 is indexed to $\mathrm{Fe}_{3} \mathrm{O}_{4}$ or $\mathrm{Fe}_{2} \mathrm{O}_{3}$. Its diameter corresponds to a lattice spacing of $2.53 \AA$, which is the spacing of the 311 planes in $\mathrm{Fe}_{3} \mathrm{O}_{4}$ (magnetite). The lowest index (111 and 200) reflections from
$\mathrm{Fe}_{3} \mathrm{O}_{4}$ would occur at diameters too small to image in this configuration. In Figure 4, a few faint spots are visible at a diameter smaller than that of the smallest complete ring. These reflections, and those of the faint spots between the second and third complete rings are indexed to $\mathrm{FeF}_{2}$. Thus, overall, the SAED pattern indicates that $\alpha$-Fe is the dominant crystalline phase present in the nanoparticles, with some small amount of $\mathrm{Fe}_{3} \mathrm{O}_{4}$ or $\mathrm{Fe}_{2} \mathrm{O}_{3}$ and an even smaller amount of $\mathrm{FeF}_{2}$ present as well. The SAED pattern in the inset of Figure 5 is not as clear as the one in Figure 4 . This is due both to the smaller particle size for the sample shown in Figure 5 and perhaps also to a lesser degree of crystallinity in that sample. The average particle size produced in experiment (2) was below $5 \mathrm{~nm}$, as seen in Figure 5. However, the rings attributable to $\alpha-\mathrm{Fe}$ and $\mathrm{Fe}_{3} \mathrm{O}_{4}$ or $\mathrm{Fe}_{2} \mathrm{O}_{3}$ that were seen in Figure 4 are still visible, except that the two highest-index rings for $\alpha$-Fe that were present in Figure 4 are not visible in Figure 5.

While the SAED pattern demonstrates that both $\alpha-\mathrm{Fe}$ and $\mathrm{Fe}_{3} \mathrm{O}_{4}$ are present, it does not tell us whether they are present in the form of $\mathrm{Fe}_{3} \mathrm{O}_{4}$ shells on $\alpha$-Fe cores, or simply as a mixture of particles of $\alpha$-Fe particles and $\mathrm{Fe}_{3} \mathrm{O}_{4}$. In high-resolution TEM images, however, we are able to identify some discrete particles with lattice spacing corresponding to the 110 and 200 planes of $\alpha$-Fe and others with lattice spacing corresponding to the 100 planes of $\mathrm{Fe}_{3} \mathrm{O}_{4}$. Examples of these are shown in Figure 6. X-Ray Photoelectron Spectroscopy (XPS) was also used to analyze the surface composition of the sample produced in Experiment (1) and it indicated that $\mathrm{C}, \mathrm{O}, \mathrm{Fe}$ and $\mathrm{F}$ were the only elements present, and that the fluorine was present as a metal fluoride. This supports the inference that $\mathrm{FeF}_{2}$ is present in the samples, from slight decomposition of the $\mathrm{SF}_{6}$ precursor. Sulfur was not detected in the solid samples. This suggests that reaction of $\mathrm{SF}_{6}$ to give $\mathrm{FeF}_{2}$ produces gaseous $\mathrm{SF}_{4}$ and/or $\mathrm{SCO}$ as a byproduct, rather than solid sulfur.

Figure 7 shows the magnetization of a sample produced using $\mathrm{C}_{2} \mathrm{H}_{4}$ as a photosensitizer, under conditions very similar to those used in experiment (2). The resulting particles were below $5 \mathrm{~nm}$ in diameter. The magnetization results show that the particles are superparamagnetic at $300 \mathrm{~K}$ with zero coercive field (no magnetic hysteresis) and the magnetization saturating at moderate field $\sim 8000$ Oe. Ideally, one can estimate the magnetic moment of an 

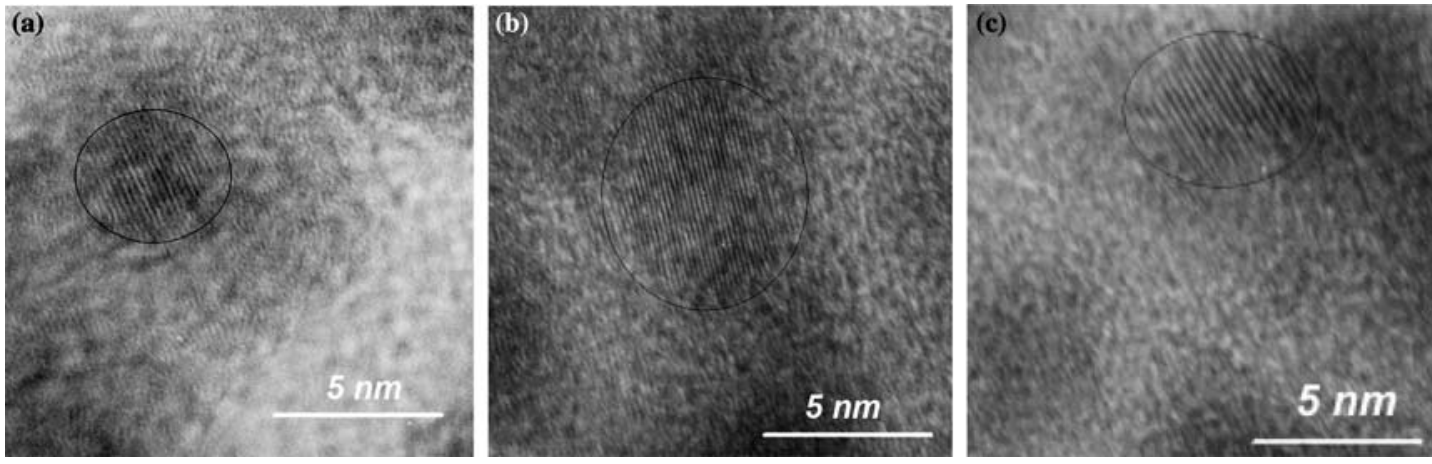

Figure 6. Lattice planes of (a) $110 \alpha-\mathrm{Fe}$, (b) $200 \alpha-\mathrm{Fe}$, and (c) $311 \mathrm{Fe}_{3} \mathrm{O}_{4}$ from nanoparticles collected in a bubbler in experiment (1).

individual particle from the mass normalized saturation magnetization. Given that the surfactant oleic acid is diamagnetic and the saturation magnetization of iron oxide $\left(\mathrm{Fe}_{3} \mathrm{O}_{4}\right)$ is low (room temperature values $480 \mathrm{G}$ for $\mathrm{Fe}_{3} \mathrm{O}_{4}$ compared to $1707 \mathrm{G}$ for $\mathrm{Fe}$ (Kittel, 2005)), an accurate knowledge of the particle size distribution, the weight fraction of the associated surfactant (determinable from a separate thermogravimetric experiment) and also that of the iron oxide phases would be needed to make this determination. This was not feasible in the present case. As per the theory of superparamagnetism, a system of monodomain magnetic particles have their intra-domain spins ferromagnetically ordered, but the net spin of each particle randomly fluctuates due to thermal activation. As an external field is imposed, the spins gradually align along the field direction and the magnetization of such a system is best described by the Langevin function

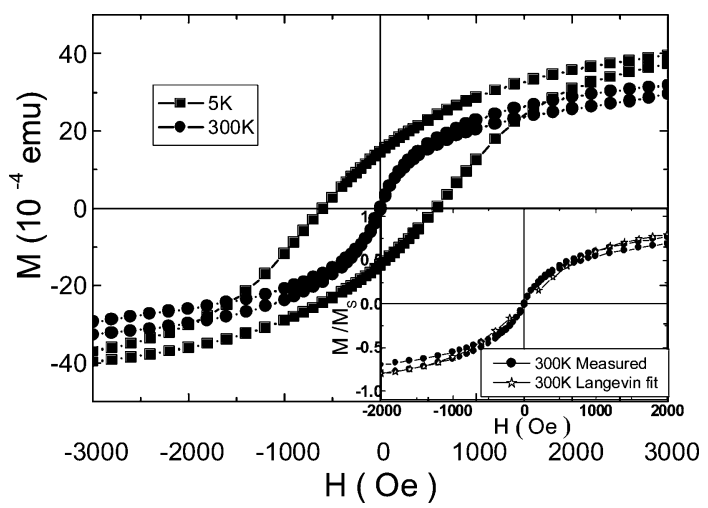

Figure 7. Magnetization of Fe particles at $300 \mathrm{~K}$ (superparamagnetic regime) and $5 \mathrm{~K}$ (blocked regime). The inset shows the Langevin function fit at $300 \mathrm{~K}$.

$$
\frac{M}{M_{\mathrm{s}}}=L(a)=\operatorname{Coth}(a)-\frac{1}{a}
$$

where $M_{\mathrm{s}}=$ saturation magnetization, $a=\mu H / k T$ and $\mu=M_{\mathrm{s}} V_{\text {avg }}$ is the particle magnetic moment for a particle of average volume $V_{\text {avg }}$, and $\mu$ is used as the fitting parameter. In the inset in Figure 7, we show a fit of our $300 \mathrm{~K}$ magnetization data to the Langevin function. When the same magnetization measurement is made at $5 \mathrm{~K}$, a hysteresis loop is observed. That is, at $5 \mathrm{~K}$ the superparamagnetic spins are blocked, implying that the blocking temperature $T_{\mathrm{B}}$ falls between 5 and $300 \mathrm{~K}$. The zero field cooled curves of magnetization vs. temperature, taken with dc fields of 50 and 100 Oersteds, indeed show broad maxima at $125-130 \mathrm{~K}$. The broadness of the $T_{\mathrm{B}}$ peak is usually attributed to size polydispersity and interparticle interactions (Sahoo et al., 2004). The

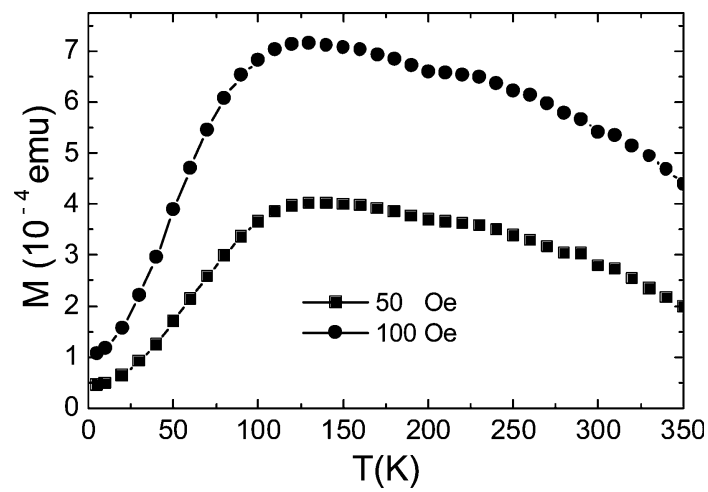

Figure 8. Zero field cooled magnetization curves of $\mathrm{Fe}$ particles. The broad blocking temperature maxima may arise from particle-particle dipolar interactions, from polydispersity in size, or a combination of these two effects. 
sample in our measurement is polydispersed. The broad peaks of $T_{\mathrm{B}}$ can be attributed to polydispersity as well as to dipolar interaction. The dipolar interaction (note the formation of a dipolar chain in Figure 4) between the particles seems to be strong.

\section{Conclusions}

Laser driven pyrolysis of iron pentacarbonyl was used to produce iron nanoparticles. Iron nanoparticles in the size range of $2-10 \mathrm{~nm}$ in diameter were collected directly into toluene with oleic acid and/or octadecylamine surfactant. Iron powder samples are extremely sensitive to oxidation by air, so that the XRD measurement was used to characterize the iron nanoparticles dispersed in toluene. The XRD result showed the characteristic peaks of crystalline $\alpha$-iron. TEM and selected area electron diffraction patterns confirmed that the iron particles are crystalline and below $10 \mathrm{~nm}$ in diameter. Both $\mathrm{SF}_{6}$ and $\mathrm{C}_{2} \mathrm{H}_{4}$ can be used as photosensitizers. When using a high $\mathrm{SF}_{6}$ flow rate, which leads to relatively high temperature in the reaction zone, $\mathrm{F}$ was present in the product nanoparticles, most likely as $\mathrm{FeF}_{2}$. Use of $\mathrm{C}_{2} \mathrm{H}_{4}$ rather than $\mathrm{SF}_{6}$ as the photosensitizer changes the particle morphology and also eliminates the possibility of fluorine contamination. Magnetization measurements on $\mathrm{Fe} / \mathrm{FeO}$ nanoparticle powder samples showed that these particles are superparamagnetic in character. Because it is known that the ligand crystal field can couple with the magnetic moments of the particles to affect their over all magnetization and also coercive field, it is both fundamentally and technologically important to control the overall magnetic behavior of the particles in this respect. In a later study, we intend to focus on the extent of spin orientations in baresurface (with no surfactant binding during growth) particles like those produced here in comparison with particles grown in solution in the presence of surface capping ligands.

\section{Acknowledgements}

This work was partially supported by a grant from the University at Buffalo (SUNY) Office of the
Vice President for Research, and by NSF ECS0224206.

\section{References}

Alexandrescu R., I. Morjan, A. Crunteanu, S. Cojocaru, S. Petcu, V. Teodorescu, F. Huisken, B. Kohn \& M. Ehbrecht, 1998. Mater. Chem. Phys. 55, 115.

Andres R.P. \& A.T. Ng 2003. PCT Int. Appl. 62.

Cannon W.R., S.C. Danforth, J.H. Flint, J.S. Haggerty \& R.A. Marra, 1982a. J. Am. Ceramic Soc. 65, 324.

Cannon W.R., S.C. Danforth, J.S. Haggerty \& R.A. Marra, 1982b. J. Am. Ceramic Soc. 65, 330.

Chen M., S. Yamamuro, D. Farrell \& S.A. Majetich, 2003. J. Appl. Phys. 93, 7551.

Chen Y.J., M.S. Cao, Q. Tian, T.H. Wang \& J. Zhu, 2004. Mater. Lett. 58, 1481.

Choi C.J., X.L. Dong \& B.K. Kim, 2001. Scripta Mater. 44, 2225.

Choi C.J., O. Tolochko \& B.K. Kim, 2002. Mater. Lett. 56, 289.

Cireasa R., R. Alexandrescu, I.M. Voicu \& I.G. Pugna, 1996. Surf. Coat. Technol. 80, 229.

Dong X.L., C.J. Choi \& B.K. Kim, 2002. J. Appl. Phys. 92, 5380.

Ge F., L. Chen, W. Ku \& J. Zhu, 1997. NanoStruct. Mater. 8, 703.

Held G.A., H. Zeng \& S. Sun, 2004. J. Appl. Phys. 95, 1481.

Hseih C.T., W.L. Huang \& J.T. Lue, 2002. J. Phys. Chem. Solids 63, 733.

Huber D.L., E.L. Venturini, J.E. Martin, P.P. Provencio \& R.J. Patel, 2004. J. Magnet. Magnetic Mater. 278, 311.

Jeyadevan B., A. Hobo, K. Urakawa, C.N. Chinnasamy, K. Shinoda \& K. Tohji, 2003. J. Appl. Phys. 93, 7574.

Jonsson B.J., T. Turkki, V. Strom, M.S. El-Shall \& K.V. Rao, 1996. J. Appl. Phys. 79, 5063.

Kinoshita T., S. Seino, K. Okitsu, T. Nakayama, T. Nakagawa \& T.A. Yamamoto, 2003. J. Alloys Compounds 359, 46.

Kittel C., 2005. Introduction to Solid State Physics. Hoboken, New Jersey: John Wiley \& Sons.

Li Q., H. Li, V.G. Pol, I. Bruckental, Y. Koltypin, J. CalderonMoreno, I. Nowik \& A. Gedanken, 2003a. New J. Chem. 27, 1194.

Li X., Y. He, S.S. Talukdar \& M.T. Swihart, 2003b. Langmuir 19, 8490.

Martelli S., O. Bomati-Miguel, L. de Dominicis, R. Giorgi, F. Rinaldi \& S. Veintemillas-Verdaguer, 2002. Appl. Surf. Sci. 186, 562.

McIlroy D.N., J. Huso, Y. Kranov, J. Marchinek, C. Ebert, S. Moore, E. Marji, R. Gandy, Y.-K. Hong, M. Grant Norton, E. Cavalieri, R. Benz, B.L. Justus \& A. Rosenberg, 2003. J. Appl. Phys. 93, 5643.

Menendez J.L., B. Bescos, G. Armelles, R. Serna, J. Gonzalo, R. Doole, A.K. Petford-Long \& M.I. Alonso, 2002. Phys. Rev. B: Condensed Matter Mater. Phys. 65, 205413/1.

Pankhurst Q.A., J. Connolly, S.K. Jones \& J. Dobson, 2003. J. Phys. D: Appl. Phys. 36, R167.

Pithawalla Y.B., M.S. El-Shall, S.C. Deevi, V. Stroem \& K.V. Rao, 2001. J. Phys. Chem.B 105, 2085. 
Plank C., U. Schillinger, F. Scherer, C. Bergemann, J.-S. Remy, F. Kroetz, M. Anton, J. Lausier \& J. Rosenecker, 2003. Biol. Chem. 384, 737.

Pol V.G., M. Motiei, A. Gedanken, J. Calderon-Moreno \& Y. Mastai, 2003. Chem. Mater. 15, 1378.

Sahoo Y., M. Cheon, S. Wang, H. Luo, E.P. Furlani \& P.N. Prasad, 2004. J. Phys. Chem. B 108, 3380.

Signoretti S., L. Del Bianco, L. Pasquini, G. Matteucci, C. Beeli \& E. Bonetti, 2003. J. Magnet. Magnetic Mater. 262, 142.

Tartaj P., M.D. Morales, S. Veintemillas-Verdaguer, T. Gonzalez-Carreno \& C.J. Serna, 2003. J. Phys. D-Appl. Phys. 36, R182.
Veintemillas-Verdaguer S., O. Bomati, M.P. Morales, P.E. Di Nunzio \& S. Martelli, 2003. Mater. Lett. 57, 1184.

Veintemillas-Verdaguer S., O. Bomati-Miguel \& M.P. Morales, 2002. Scripta Mater. 47, 589.

Veintemillas-Verdaguer S., M.P. Morales \& C.J. Serna, 1998. Mater. Lett. 35, 227.

Wu R. \& C. Xie, 2003. Mater. Lett. 57, 1539.

Ye F., M.C. Yang, X.K. Sun \& W.D. Wei, 1997. Nanostruct. Mater. 9, 113.

Zhang W.-X., 2003. J. Nanoparticle Res. 5, 323.

Zhao X.Q., F. Zheng, Y. Liang, Z.Q. Hu \& Y.B. Xu, 1994. Mat. Lett. 21, 285. 